\title{
ALTERED APOPTOTIC PROTEIN EXPRESSIONS CHARACTERIZE THE SURVIVAL OF BCR-ABL-INDEPENDENT DRUG-RESISTANT CHRONIC MYELOID LEUKEMIA CELL LINE
}

\author{
Seda Baykal-Kose ${ }^{1}$, Pelin Yalcin ${ }^{1}$ \\ ${ }^{1}$ Dokuz Eylül University, Medical School, Medical Biology Dept., İzmir, Turkey \\ Address for Correspondence: Dr.Seda Baykal-Kose, , E-mail: seda.baykalkose@gmail.com \\ Received: 28.12.2020; Accepted: 05.01.2021; Available Online Date: 04.03.2021 \\ (C)opyright 2020 by Dokuz Eylül University, Institute of Health Sciences - Available online at https://dergipark.org.tr/tr/pub/jbachs
}

Cite this article as: Kose Baykal S, Yalcin P. Altered apoptotic protein expressions characterize the survival of Bcr-Ablindependent drug-resistant chronic myeloid leukemia cell line. J Basic Clin Health Sci 2021; 1: 1-5.

\begin{abstract}
Apoptosis is a programmed cellular process that occurs in pathological and physiological pathways and it is one of the most studied topics in cell biology. To understand the underlying mechanism of apoptosis plays an important role in the molecular pathogenesis of many diseases including cancers. Chronic myeloid leukemia $(\mathrm{CML})$ is a clonal myeloproliferative malignancy arising from the neoplastic transformation of the hematopoietic stem cell. Here, we used a Bcr-Abl-independent, imatinib-resistant K562 subpopulation (K562-IR) generated and characterized earlier in our laboratory. We showed that the proteins $\mathrm{Bcl}-2$, Bim, RIP, p-MAPK(Erk1/Erk2) and NF-kB which plays critical roles in cell death pathways are downregulated, Lamin A/C protein expression is upregulated in K562-IR derivative cells compared to K562 ancestral cells. Our data provides new information on the expression of apoptotic molecules in a Bcr-Abl-independent imatinib-resistant CML cell line.
\end{abstract}

Keywords: Chronic myeloid leukemia, apoptosis, Bcl-2, Bim, RIP, NF-kB

\section{INTRODUCTION}

Understanding the cell death and survival mechanisms is crucial for the development of new therapy strategies and novel drugs in malignant diseases. Apoptosis is the first characterized form of programmed cell death. Signaling pathways leading to apoptosis are well conserved between species (1, 2). Apoptosis may be induced in a cell via extrinsic and/or intrinsic pathways, both which converge on the activation of caspase-dependent proteolysis of thousands of cellular proteins. Membrane blebbing and endonucleolytic cleavage of chromosomal DNA are predominant features. Defects in this process is related to unregulated cell survival and drug resistance. Resistance to apoptosis is one of the main features observed in a malignant transformed cell (3$5)$. 
Chronic myeloid leukemia (CML) is a hematopoietic stem cell disease that occurs as a result of the reciprocal translocation between the chromosomes 9 and 22. The resulting derivative chromosome 22 is known as the Philadelphia chromosome. The Bcr-Abl fusion protein resulting from this translocation exhibits an unregulated, continuous tyrosine kinase activity that allows the expansion of the leukemic clones by triggering signaling pathways, leading to cell proliferation, transcriptional activity and resistance to apoptosis. Bcr-Abl oncoprotein phosphorilates various downstream substrates that regulate the apoptotic machinery in the cell (6-8). Imatinib mesylate (STI-571), a tyrosine kinase inhibitor targeting the Bcr-Abl oncoprotein, inhibits the enzymatic activity of Bcr-Abl and as a result has been associated with the induction of apoptosis in leukemic cells (9-11). On the other hand, imatinib resistance is an important problem affecting $30 \%$ of $\mathrm{CML}$ patients and studies in this area aim to reveal treatment resistance mechanisms. There are several Bcr-Abl dependent resistance mechanisms in which BCR$\mathrm{ABL}$ amplifications/duplications, Bcr-Abl oncoprotein secondary kinase domain mutations are most frequently observed. Bcr-Abl independent mechanisms have been shown in CML cancer stem cells and are still being investigated (12-16). In this study, we aimed to study Bcl-2, Bim, RIP, NFkB, Lamin $A / C$ and Erk1/Erk2 protein expression levels, which may have pivotal roles in the cell death pathway in a Bcr-Abl independent imatinib-resistant CML cell line model.

\section{METHODS}

\section{Cell lines and Cell Culture}

Human chronic phase myeloid leukemia cell line K562 was obtained from ATCC. A resistant subclone, K562-IR was generated by clonal selection under imatinib mesylate selective pressure (17). Cells were subject to increasing imatinib doses starting at $0.1 \mu \mathrm{M}$ and the final dose was $10 \mu \mathrm{M}$ which is two-fold higher than the serum concentration of patients with a daily uptake of $400 \mathrm{~g}$ imatinib (11). We generated a imatinib resistant sub-population under these conditions. Cells were cultured in RPMI 1640 with $10 \%$ fetal bovine serum (FBS), 1 unit $/ \mathrm{mL} P / S$ at $37^{\circ} \mathrm{C}$ and $5 \% \mathrm{CO}_{2}$. The imatinib resistant $\mathrm{K} 562$ clone, K562-IR was continuously cultured with $10 \mu \mathrm{M}$ imatinib; while
$10 \mu \mathrm{M}$ imatinib was added to $\mathrm{K} 562$ cells in appropriate experimental conditions to serve as control.

\section{Western blot analysis}

Protein lysates were prepared from K562 and K562IR cells with RIPA buffer. Proteins were quantified by BCA assay. The proteins were separated by polyacrylamide gel electrophoresis and wet transferred to PVDF membranes. Membranes were probed with specific antibodies and visualized by the sensitive X-ray films. Antibodies used are human antiB-actin HRP (Sigma A3854), human anti-elF4E (Cell Signaling \#2067), human anti-Lamin A/C (Cell signaling \#4777), human anti-Bim (ab7888), human anti-RIP (ab106393), human anti-NFkB (ab209795), human anti-phospho-p44/42 MAPK (Erk1/2) (Thr202/Tyr204) (Cell signaling \#4376)

\section{RESULTS}

Cellular characteristics of K562-IR cells were reported in our previous study (17). Pro- and antiapoptotic protein expressions are altered in ancestral K562 and derived K562-IR cells Western blot analysis was performed for K562 and K562-IR cells with and without imatinib culture conditions (24h). The antiapoptotic protein $\mathrm{Bcl}-2$ is downregulated in $\mathrm{K} 562-\mathrm{IR}$ resistant cells. On the other hand, pro-apoptotic protein Bim expression is upregulated in $\mathrm{K} 562$ cells and imatinib presence increases its expression. Conversely, Bim expression of K562-IR cells is quite low and it is not dependent on imatinib presence. Erk1 and Erk2 phosphorylations are interrupted in K562-IR cells that are cultured continuously in $10 \mu \mathrm{M}$ imatinib. NF-kB (p100/p50) expression is downregulated in K562-IR cells. RIP expression does not differ between K562 and K562-IR cells but in the presence of imatinib, RIP expression is dowregulated in K562-IR cells. In addition, Lamin A/C expression was found to be upregulated in the K562-IR cell line (Fig. 1).

\section{DISCUSSION}

To understand the underlying mechanism of apoptosis plays a pivotal role in the pathogenesis of cancers. In this study we used an K562-derived, tyrosine kinase inhibitor resistant cell line K562-IR, obtained by clonal selection under imatinib pressure to investigate apoptotic pathway differences between 

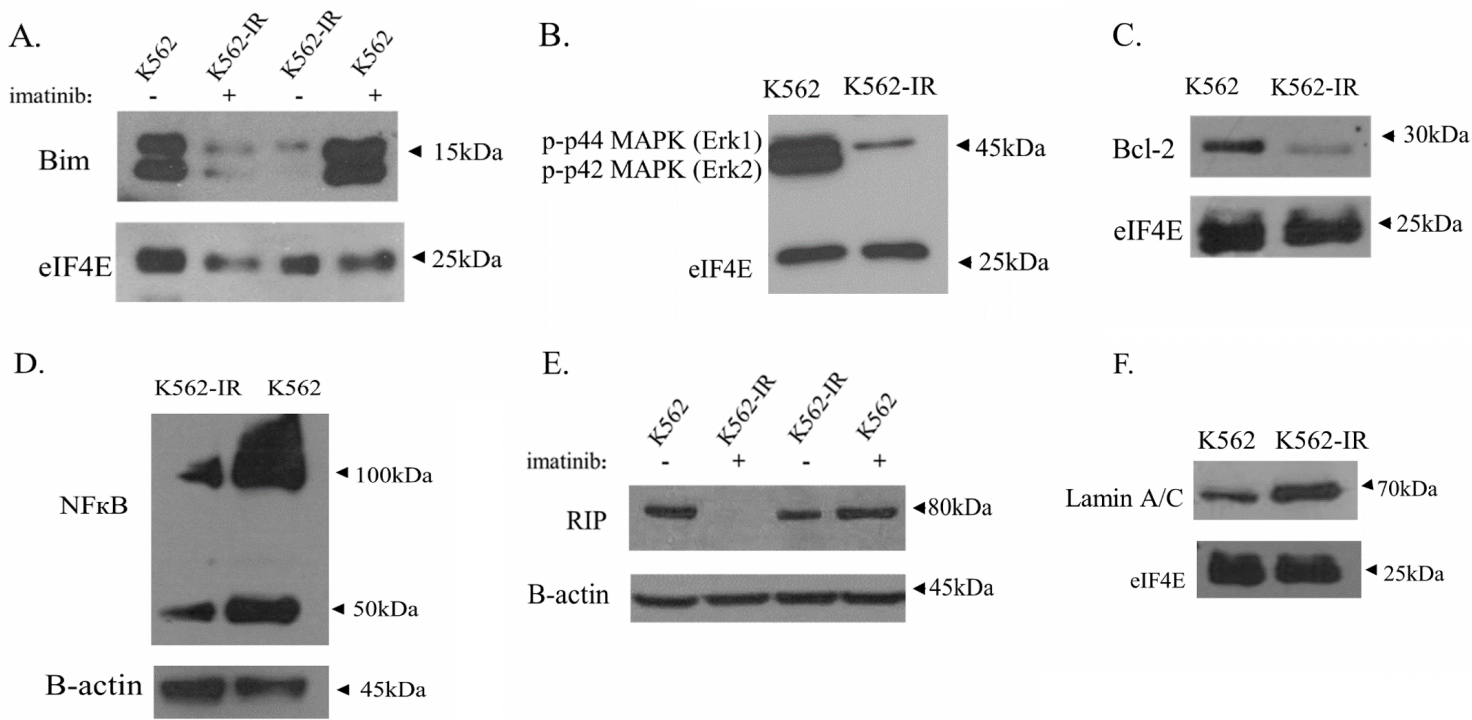

F.

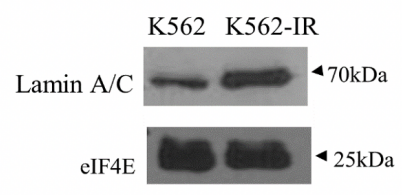

Figure 1. Apoptotic pathway results of ancestral K562 and derived K562-IR cells. Western blot analysis were performed for $\operatorname{Bim}(A)$, phosphorilated MAP kinase (B), Bcl-2 (C), NFKB (D), RIP (E) and Lamin A/C (F)proteins. K562 cells were treated with $1 \mu \mathrm{M}$ imatinib for $24 \mathrm{~h}$ before the experiment ( $\mathrm{A}$ and $\mathrm{E})$. K562-IR cells were continuously cultured with $10 \mu \mathrm{M}$ imatinib. For without imatinib (-) samples K562-IR cells were washed twice with PBS and cultured for $24 \mathrm{~h}$ before the experiment (A and E). $\beta$-actin and elF4E proteins are used for loading control.

imatinib sensitive and imatinib resistant CML cells. K562-IR cells are resistant to imatinib, dasatinib, ponatinib, nilotinib and bosutinib tirosine kinase inhibitors (TKIs), they display a semi-adherent phenotype, they are Bcr-Abl independent, and their proliferation rate is 4-fold slower than the K562 cell line (17). They represent cells that have gained an inherent resistance to TKIs when challenged over time, by biologically becoming Bcr-Abl independent; thus not relying on this oncoprotein's signaling as a survival signal.

$\mathrm{Bcl}-2$ protein family have both proapoptotic (e.g., Bim and Bak) and antiapoptotic (e.g., Bcl-2 and $\mathrm{Bcl}-\mathrm{XL}$ ) members which are responsible for the initiation of apoptosis by regulating the release cytochrome $c$ from mitochondria (18). While anti-apoptotic protein $\mathrm{Bcl}-2$ inhibits this process, the pro-apoptotic molecule Bim interacts with $\mathrm{Bcl}-2$ to suppress its activity and drive the cell to apoptosis (19). Bim, Bcl-2 and ERK1/2 phosphorylation plays important roles in BcrAbl driven apoptotic pathways (20). Imatinib also suppresses the PDGFR signaling pathway along with the Bcr-Abl pathway. ERK $1 / 2$ phosphorylation is a downstream effector molecule of PDGFR signaling and is therefore inhibited in K562-IR cells which are grown under continuous 10uM imatinib pressure (Fig1.B) The anti-apoptotic Bcl-2 protein expression is expected to be upregulated in K562-IR cells which have high survival capacity, but surprisingly its expression was shown to be lower when compared to K562 cells (Fig.1C).

On the other hand Bim protein expression is abundant in K562 cells and its expression is upregulated by imatinib; whereas Bim is expression is downregulated in K562-IR cells and does not change in the presence or absence of imatinib (Fig.1A).

These result show that apoptosis is triggered and changes of in the Bcl-s family of proteins are observed accordingly in the presence of imatinib, in TKI sensitive wild-type K562 cells. Whereas in the TKI resistant K562-IR cells, presence of imatinib has no influence on $\mathrm{Bcl}-2$ apoptosis signaling. Bim, which blocks the anti-apoptotic activity of the $\mathrm{Bcl}-2$ protein is downregulated leading to a general resistance to apoptotic cell death. On the other hand, $\mathrm{Bcl}-2$ protein expression is not triggered in these Bcr-Abl independent cells due to not sensing a threat by the presence of imatinib. Also it's known that RIP kinase 
regulates $\mathrm{Bcl}-2$ protein activity through its interactions with MAPK/NFKB (21); which may explain the the downregulation of Bcl-2 in the K562-IR cells.

RIP kinase usually functions in the programmed necroptosis pathways and participates in extrinsic apoptotic pathways (22-24). Information on the role of RIP kinase in CML literature is quite limited. Studies have shown that RIP overexpression can activate NFKB through TNF receptor-associated proteins. In RIP-deficient cells, TLR3- mediated NF$\mathrm{kB}$ activation is decreased (25-28). Our results show that RIP expression is inhibited in K562-IR cells which are continuously cultured with imatinib and as expected NFKB expression is also downregulated (Fig1.D and E). Whereas in wild-type K562 cells, the presence of imatinib does not effect RIP expression (Fig1.E).

Lamins $\mathrm{A}$ and $\mathrm{C}$ are structural intermediate filament proteins which provide stability and strength to cells, especially to the nuclear envelope. Lamins are specifically targeted by caspases 3 and 6 that become activated both through the intrinsic and extrinsic apoptotic pathways(29). They are expressed in myeloid leukemia cells (30). There are studies that show normally proliferative or not proliferative cells are devoid of A-type lamin expression, while many neoplastic tissues show remarkable lamin expression levels(30). Our results show that Lamin $A / C$ expressions are downregulated in slow proliferative K562-IR cell (Fig.1F).

Our results provide information on the expression profile of apoptotic molecules in a Bcr-Abl independent imatinib-resistant $\mathrm{CML}$ cell line model and contributes to the studies of CML biology and to the drug development technologies. More research is needed to elucidate the precise mechanisms that these molecules exert their effects.

Acknowledgement: The authors gratefully acknowledge to $\mathrm{Dr}$ Zeynep Yüce for her valuable comments to our work. Peer-review: Externally peer-reviewed.

\section{REFERENCES}

1. Ellis RE, Yuan J, and Horvitz HR. Mechanisms and functions of cell death. Vol. 7, Annual Review of Cell Biology. Annu Rev Cell Biol; 1991; 663698.
2. Ellis HM and Horvitz HR. Genetic control of programmed cell death in the nematode $\mathrm{C}$. elegans. Cell 1986; 44:817-829.

3. Pistritto G, Trisciuoglio D, Ceci C, Alessia Garufi, and D'Orazi G. Apoptosis as anticancer mechanism: Function and dysfunction of its modulators and targeted therapeutic strategies. Vol. 8, Aging. Impact Journals LLC; 2016; 603619.

4. Pfeffer CM and Singh ATK. Apoptosis: A target for anticancer therapy. Vol. 19, International Journal of Molecular Sciences. MDPI AG; 2018.

5. Wong RSY. Apoptosis in cancer: From pathogenesis to treatment. Vol. 30, Journal of Experimental and Clinical Cancer Research. BioMed Central; 2011; 87.

6. Quintás-Cardama A and Cortes J. Molecular biology of bcr-abl1-positive chronic myeloid leukemia. Blood 2009; 113:1619-30.

7. Deininger MWN, Goldman JM, Melo J V, Dc W, Deininger MWN, Goldman JM, et al. The molecular biology of chronic myeloid leukemia Review article The molecular biology of chronic myeloid leukemia. 2000; 96:3343-3356.

8. Seke Etet PF, Vecchio L, and Nwabo Kamdje $\mathrm{AH}$. Signaling pathways in chronic myeloid leukemia and leukemic stem cell maintenance: Key role of stromal microenvironment. Cell Signal 2012; 24:1883-1888.

9. Yilmaz $M$ and Jabbour $E$. Tyrosine Kinase Inhibitors Early in the Disease Course: Lessons From Chronic Myelogenous Leukemia. Semin Oncol 2015; 42:876-886.

10. Hochhaus a, O'Brien SG, Guilhot F, Druker BJ, Branford S, Foroni L, et al. Six-year follow-up of patients receiving imatinib for the first-line treatment of chronic myeloid leukemia. Leukemia 2009; 23:1054-61.

11. Deininger MWN and Druker BJ. Specific Targeted Therapy of Chronic Myelogenous Leukemia with Imatinib. Pharmacol Rev 2003; 55:401-423.

12. Assouline $\mathrm{S}$ and Lipton $\mathrm{JH}$. Monitoring response and resistance to treatment in chronic myeloid leukemia. Curr Oncol 2011; 18:e71-83.

13. 13. Bixby $D$ and Talpaz M. Mechanisms of resistance to tyrosine kinase inhibitors in chronic myeloid leukemia and recent therapeutic strategies to overcome resistance. Hematology 2009; 2009:461-476.

14. O'Hare T, Eide CA, and Deininger MWN. Bcr-Abl kinase domain mutations, drug resistance, and the road to a cure for chronic myeloid leukemia. Blood 2007; 110:2242-2249.

15. Corbin AS, Agarwal A, Loriaux M, Cortes J, Deininger $\mathrm{MW}$, and Druker BJ. Human chronic myeloid leukemia stem cells are insensitive to 
imatinib despite inhibition of BCR-ABL activity. J Clin Invest 2011; 121:396-409.

16. Mitchell R, Hopcroft LEM, Baquero P, Allan EK, Hewit $\mathrm{K}$, James $\mathrm{D}$, et al. Targeting BCR-ABLindependent TKI resistance in chronic myeloid leukemia by mTOR and autophagy inhibition. J Natl Cancer Inst 2018; 110:467-478.

17. Baykal-Köse S, Acikgoz E, Yavuz AS, Geyik ÖG, Ateş $\mathrm{H}$, Sezerman OU, et al. Adaptive phenotypic modulations lead to therapy resistance in chronic myeloid leukemia cells. PLoS One 2020; 15:119.

18. Danial NN and Korsmeyer SJ. Cell Death: Critical Control Points. Vol. 116, Cell. Cell Press; 2004; 205-219.

19. Ewings KE, Wiggins CM, and Cook SJ. Bim and the pro-survival Bcl-2 proteins: Opposites attract, ERK repels. Vol. 6, Cell Cycle. Taylor and Francis Inc.; 2007; 2236-2240.

20. Kaufmann SH. Imatinib spells BAD news for Bcr/abl-positive leukemias. Vol. 103, Proceedings of the National Academy of Sciences of the United States of America. 2006; 14651-14652.

21. Martens S, Hofmans S, Declercq W, Augustyns $K$, and Vandenabeele $P$. Inhibitors Targeting RIPK1/RIPK3: Old and New Drugs. Trends Pharmacol Sci 2020; 41:209-224.

22. Zhang X, Dowling JP, and Zhang J. RIPK1 can mediate apoptosis in addition to necroptosis during embryonic development. Cell Death Dis 2019; 10:1-11.

23. Dhuriya YK and Sharma D. Necroptosis: A regulated inflammatory mode of cell death. Vol. 15, Journal of Neuroinflammation. BioMed Central Ltd.; 2018.

24. Galluzzi L, Kepp O, and Kroemer G. RIP kinases initiate programmed necrosis. J Mol Cell Biol 2009; 1:8-10.

25. Aggarwal BB. Tumour necrosis factors receptor associated signalling molecules and their role in activation of apoptosis, JNK and NF-KB. In: Annals of the Rheumatic Diseases. BMJ Publishing Group Ltd; 2000; i6-i16.

26. Kawai T and Akira S. Signaling to NF-kB by Tolllike receptors. Trends Mol Med 2007; 13:460469.

27. Cusson-Hermance $\mathrm{N}$, Khurana $\mathrm{S}$, Lee $\mathrm{TH}$, Fitzgerald KA, and Kelliher MA. Rip1 mediates the trif-dependent Toll-like receptor 3- and 4induced NF-KB activation but does not contribute to interferon regulatory factor 3 activation. J Biol Chem 2005; 280:36560-36566.

28. Hsu H, Huang J, Shu HB, Baichwal V, and Goeddel D V. TNF-dependent recruitment of the protein kinase RIP to the TNF receptor-1 signaling complex. Immunity 1996; 4:387-396.
29. Okinaga $T$, Kasai $H$, Tsujisawa $T$, and Nishihara $\mathrm{T}$. Role of caspases in cleavage of lamin A/C and PARP during apoptosis in macrophages infected with a periodontopathic bacterium. J Med Microbiol 2007; 56:1399-1404.

30. Broers JLV and Ramaekers FCS. The role of the nuclear lamina in cancer and apoptosis. Adv Exp Med Biol 2014; 773:27-48. 